\title{
Currents, Waves and Turbulence Measurement: A view from multiple Industrial-Academic Projects in Tidal Stream Energy
}

\author{
Mairi Dorward $^{1}$, Brian Sellar ${ }^{1}$, Chris Old ${ }^{1}$, Philipp R. Thies ${ }^{2}$
}

\begin{abstract}
Tidal Stream Energy is considered a regular, predictable and dense energy source with potential to make a significant contribution to our future energy needs. Development of the industry, from resource assessment to device design and operation, requires characterisation of the flow environment at a variety of spatial and temporal scales at tidal energy sites. Demand for flow characterisation arises from companies developing, installing and operating tidal turbine prototypes or small arrays in locations from Scotland to France to Canada.

Flow characterisation for tidal stream applications relies on the measurement of water velocity at the relevant scales, yet given the non-uniformity of the flow field, no single instrument measures all the necessary data inputs required by the sector. This paper provides an overview of a variety of current, surface wave and turbulence metrics of industrial relevance to tidal stream and discusses methods employed to secure these datasets. The use of variants of acoustic current profilers is presented, which have been utilised and developed on previous and ongoing industrialacademic projects, including ReDAPT (ETI, UK), FloWTurb (EPSRC, UK) and RealTide (EC H2020, EU). These variants feature differing numbers of acoustic transducers and varying geometrical configurations with installations at both seabed locations and atop operating tidal stream energy converters.

Ongoing development of advanced sensor configuration is discussed, aiming to achieve resilient, high resolution threedimensional measurement of mean and turbulent flow tailored for tidal energy applications.
\end{abstract}

The paper gives practitioners and researchers an overview of tidal stream flow characterisation and practical lessons learnt.

\section{INTRODUCTION}

Tidal Stream Energy has the potential to make a significant contribution to our future energy needs, indeed by 2050 tidal energy could meet $10 \%$ of European electricity requirements [1]. While tidal stream is considered a reliable and predictable source of dense, renewable and low-carbon energy, the complexity of the associated flow environment poses many challenges for flow characterisation and the development of the sector. Variation in the flow environment occurs at tidal energy sites at spatial scales which range from kilometers (e.g. large scale eddy structures) to blade lengths and smaller (e.g. microscale eddies) and at temporal scales ranging from years (solar/lunar cycle) to seconds (turbulent gusts) [2]. As illustrated in Fig. 1, non-uniformity in the flow field results from a variety of factors such as high shear in the velocity profile, surface waves, turbulence and bathymetric interaction.

\footnotetext{
${ }^{1}$ M. Dorward, C. Old and B. Sellar are with the School of Engineering, University of Edinburgh, Old College, South Bridge, Edinburgh, EH8 9YL, UK, m.dorwardled.ac.uk; c.oldled.ac.uk; brian.sellarded.ac.uk

${ }^{2}$ P.R. Thies is with the University of Exeter, College of Engineering, Mathematics and Physical Sciences, Renewable Energy Group, Penryn, Cornwall, TR10 9FE, UK p.r.thiesdexeter.ac.uk
}

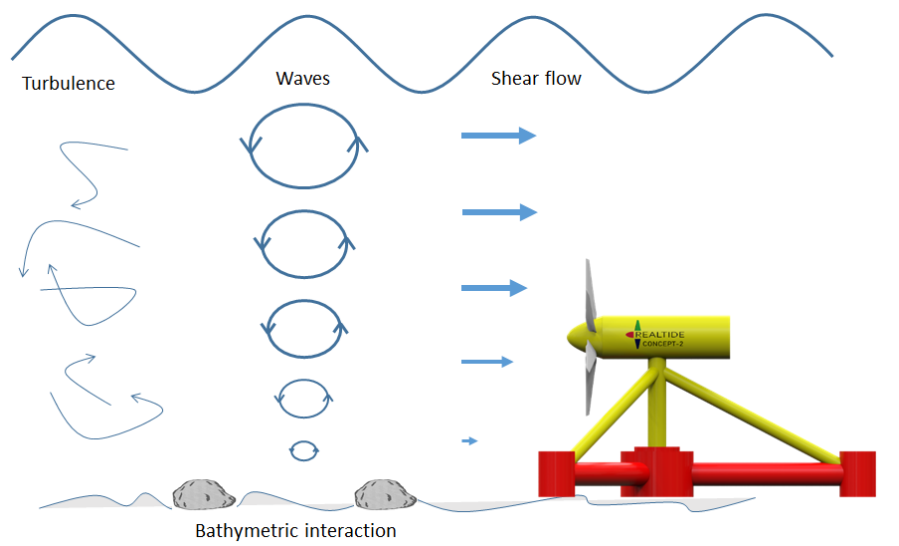

Fig. 1. Factors causing non-uniformity in the flow field around a tidal turbine, after [3]

Flow characterisation for the tidal sector aims to generate input data relevant to engineering models that are used to assess loads and resource availability and to plan on-site activity such as installation and maintenance. To support the industry in its early stage of commercialistion, ultimately leading to cost effective and reliable power production, reductions are required in measurement uncertainty in the highly heterogeneous tidal channel environment. Drawing on the experience of the authors and from the implementation of multiple projects [4] [5] [6], flow characterisation data should not be acquired in isolation. As shown in Fig. 2, data acquisition should be informed by, and inform, multi-scale hydrodynamic models. Data management and processing should reliably allow users outwith the data acquisition team to access, understand and use the data, confident of its quality. Users of engineering tools should also provide feedback to flow measurement campaign designers in order to ensure acquisition of relevant metrics and associated data which can be used to inform and validate tools.

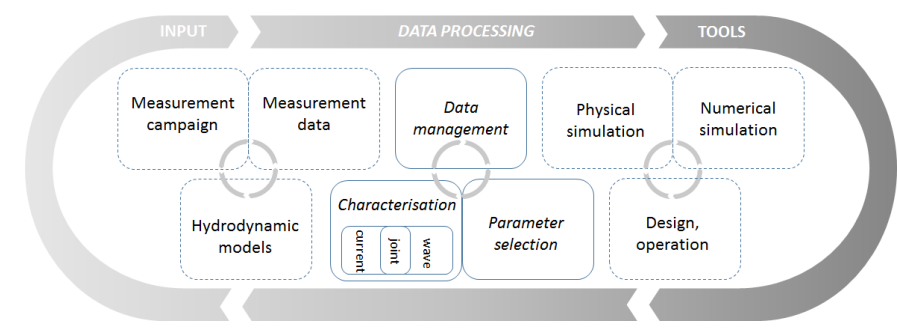

Fig. 2. Feedback between a measurement campaign and the engineering tools utilising the resultant data, developed from [7] 
This article is laid out as follows: a brief overview of the tidal industry is provided in Section 2. Section 3 presents an overview of current, wave and turbulence metrics, highlighting aspects of industrial application. Section 4 discusses the instruments used to obtain these industrially relevant metrics and Section 5 reviews several major industrial/academic projects where these instruments have been deployed to obtain these metrics. Section 6 summarises ongoing development of advanced configurations of Tidal Energy Converter (TEC)associated instruments, based on lessons learned from the industry/academic consortia.

\section{THE INDUSTRY}

Sites suitable for tidal stream TEC deployment are typically those which, as a minimum, have a water depth of 25 to $45 \mathrm{~m}$, which can be connected to an electrical grid and which have a peak spring tide velocity of at least $3 \mathrm{~m} / \mathrm{s}$ [8]. Three generic designs of TEC and associated deployment locations are identified in Table I. In each, a horizontal axis turbine utilises one of a variety of designs (e.g. number of blades, ability to pitch and yaw, complexity), sizes (e.g. rotor diameter, rated power capacity) and modes of operation (floating or gravity based).

The tidal industry faces many challenges, epitomised by the recent liquidation of tidal energy company OpenHydro and near bankruptcy of developer, Tocardo. Nevertheless, there remains considerable activity globally. In the UK, SIMEC Atlantis Energy in the Pentland Firth are operating 4 x $1.5 \mathrm{MW}$ grid-connected turbines with plans to extend this array with another two turbines and a regulatory lease in place for the installation of up to $398 \mathrm{MW}$. Orbital Marine Power operated a $2 \mathrm{MW}$ prototype floating turbine for 2 years in Orkney, generating over 3,000 MWh of electricity and are now developing a floating $2 \mathrm{MW}$ commercial demonstrator. Nova Innovation are operating a 3 x $100 \mathrm{~kW}$ turbine array in Shetland with plans to extend this array by a further 3 turbines to enable field investigation of array interaction. Magallanes Renovables, from Spain, are building on previous ocean testing of a tenth scale prototype with the deployment of a $2 \mathrm{MW}$ tidal platform in Orkney. In France, Sabella are operating a $1 \mathrm{MW}$ turbine in the Fromveur Strait, following which the installation of $2 \times 500 \mathrm{~kW}$ turbines is planned in the same area. In Nova Scotia, Canada, Sustainable Marine Energy are operating a floating platform hosting 4 x $250 \mathrm{~kW}$ turbines, focussing on community scale systems. ${ }^{1}$

Current, wave and turbulence metrics - and the interaction between these processes - are used to predict available resource, to determine power quality fluctuations and to assess fatigue and extreme loading of TECs [2]. Required both for individual TECs and interactions between arrays of TECs, incorporation of these metrics into engineering tools informs design. This contributes to the reliable and predictable production of grid quality power at costs competitive with other forms of energy generation - paramount for the future growth and development of the tidal industry [9].

\footnotetext{
${ }^{1}$ Information in paragraph sourced from web searches
}

TABLE I

GENERIC TYPes of TidAl ENERgy CONVERTER (CREDIT: REALTIDE/ENEROCEAN)

\begin{tabular}{|c|c|c|c|}
\hline Generic classification & Key features & Image & $\begin{array}{l}\text { Example companies, } \\
\text { deployment location }\end{array}$ \\
\hline $\begin{array}{l}\text { Complex bottom } \\
\text { fixed tidal turbine }\end{array}$ & $\begin{array}{l}\text { Horizontal axis } \\
\text { Open rotor } \\
3 \text { blades } \\
\text { Bottom fixed } \\
\text { Pitch control } \\
\text { Yaw mechanism } \\
\text { Gearbox drive }\end{array}$ & & $\begin{array}{l}\text { SIMEC Atlantis Energy } \\
\text { Pentland Firth, Scotland } \\
\text { https://simecatlantis.com/ }\end{array}$ \\
\hline $\begin{array}{l}\text { Simple bottom } \\
\text { fixed tidal turbine }\end{array}$ & $\begin{array}{l}\text { Horizontal axis } \\
\text { Open rotor } \\
\text { Multi blade } \\
\text { Bottom fixed } \\
\text { No pitch control } \\
\text { No yaw mechanism } \\
\text { Direct drive }\end{array}$ & & $\begin{array}{l}\text { Sabella } \\
\text { Fromveur Strait, France } \\
\text { https://www.sabella.bzh/en } \\
\text { Nova Innovation } \\
\text { Bluemull Sound, Shetland, Scotland } \\
\text { https://www.novainnovation.com/ }\end{array}$ \\
\hline $\begin{array}{l}\text { Floating multi-rotor } \\
\text { tidal turbine }\end{array}$ & $\begin{array}{l}\text { Horizontal axis } \\
\text { Open rotor } \\
\text { Multi blade } \\
\text { Floating } \\
\text { No active pitch mechanism } \\
\text { No active yaw mechanism } \\
\text { Gearbox drive }\end{array}$ & & $\begin{array}{l}\text { Orbital Marine Power } \\
\text { Falls of Warness, Orkney, Scotland } \\
\text { (prototype, removed Sept 2018) } \\
\text { https://orbitalmarine.com/ } \\
\text { Sustainable Marine Energy } \\
\text { Grand Passage, Nova Scotia, Canada } \\
\text { https://sustainablemarine.com/ }\end{array}$ \\
\hline
\end{tabular}




\section{METRICS OF INDUSTRIAL RELEVANCE}

In the literature a wide range of metrics exist to describe currents, waves and turbulence and may be directly measured, derived from time or frequency domain analysis or derived statistically [16], [17]. From this range of potential metrics, a subset are in frequent use by the tidal industry throughout design, planning and operation, a range of which are referenced in Table II (NB. wind metrics, which drive waves and local wave-current interactions, are excluded from this paper)

In the following, the application of these metrics to the tidal sector is considered, noting that evaluation of the effect of tidal stream energy extraction on the marine environment is outwith the scope of this paper (see e.g. [9] and [18] for review).

- Current speed and direction: TECs have a rated, cutin and cut-out current speed. Knowing the relationship between current speed and TEC power output generates a power curve which can be applied to measured/determined current speeds for a specific location to forecast energy yield [19]. Tides may not be rectilinear or symmetrical and if a TEC does not yaw, current direction is key to installation to ensure the TEC is oriented to maximise power capture during all tidal conditions. Real time control of the TEC, seeking to maximise power output while minimising loads, depends on a feedback loop between measured and/or expected current speed and operation of the TEC [20].

- Turbulence: Generated by shear instabilities, turbulence is part of the velocity field in an area and has multiple scales from vortices the width of a tidal channel to microscale eddies, millimeters in size [2]. Understanding is required of the level (turbulence intensity) and nature (lengthscale) of both ambient turbulence (i.e. natural turbulence before TECs are installed and which will occur upstream of the TECs) and also turbulence post installation [21]. This influences the understanding of TEC wake formation and dissipation, interaction between TEC wakes in an array and fluctuations in load across a swept rotor area - informing TEC design to withstand fatigue and TEC siting within an array [22]. Research continues into application to the tidal industry of turbulence theory and models which have been validated for the wind industry, given the influence of the free surface (air/sea boundary) and seabed bathymetry including bounding channels [2].

TABLE II

EXAMPLE METRICS IN USE IN THE TIDAL INDUSTRY

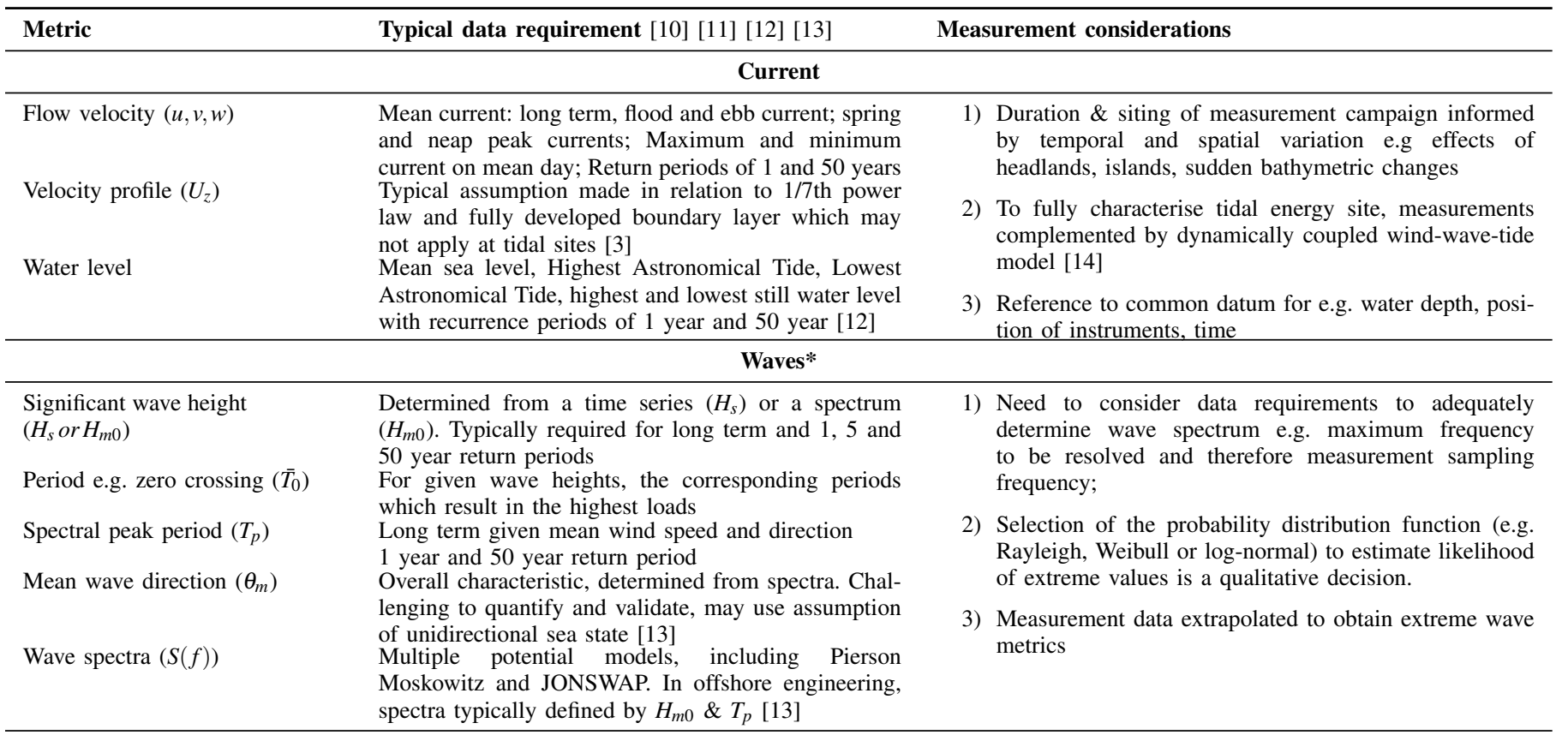

\section{Turbulence}

Turbulence Intensity $\left(I_{u}\right)$

Turbulent Kinetic Energy (TKE)

Length scale $\left(\ell_{x}\right)$

Reynolds Stress Tensor $(\bar{R})$
If turbulence is anisotropic, measurements are required in $u, v$ and $w$ directions

Measurement required in $u, v$ and $w$ directions

From measurement of $u, v$ and $w$, spectra are generated to calculate length scales via e.g. autocorrelation or von Karman fitting

Full tensor can't be obtained at hub height by single instrument. Currently 5 of 6 components can be obtained via 5-beam D-ADP [15]
1) May be over-estimated in wave-current environment given the comparable magnitude of wave \& larger turbulence length scales.

2) Not industry standard requirement in resource [10] or annual energy production assessment [11].

3) Turbulence metrics are an input to CFD for TEC and used in loading assessment [13] 
- Waves: To assess irregular sea states for TEC and component loading analysis, characterisation of waves is required by obtaining significant wave height, peak period, wave spectrum and wave direction. A simpler, yet less comprehensive methodology is to use regular waves, characterised by maximum wave height, period and direction. As waves can penetrate to significant depths in the water column, estimated to be approximately $50 \%$ of their wavelength [23], turbine blade loading can be affected, even at considerable depths.

- Wave/current interactions: While investigation of this interaction has typically been limited/neglected in field measurements, there is growing recognition of its impact on TEC loading and power capture. Waves are predicted to influence turbine power output due to the cubic relationship between power and flow velocity [24]. Waves acting on floating TECs cause them to yaw and pitch, changing their orientation in the tidal current and thus affecting the blade angle of attack. Assuming that wave and current can be added together using particle velocity vectors is too simplistic and may under or over estimate loading because [23], [24]:

- Wave-current interaction is non-linear

- There is high spatial variation in velocity (shear), introduced by e.g. the decay of the effect of wave energy with depth

- There is turbulence and surface waves

- The direction of wave and current may be following, opposing or oblique

- Forces applied to blades from waves will have circular components

Tank studies [25], [26] have demonstrated that understanding of wave-current interaction is required for TEC design so that

Current, wave and turbulence metrics are incorporated into tools which are used in engineering design and validation.

As an example, the metrics are used as input into high resolution, coupled wave and current hydrodynamic models which complement field measurement campaigns being lower cost (and risk) than field data acquisition which will always produce relatively sparse and localised data in comparison.
Hydrodynamic models can generate representative site conditions (normal conditions used to determine fatigue loading) and be used to evaluate the impact of extreme conditions (infrequent conditions which occur with a statistical probability that can lead to extreme loading on the TEC e.g. 50 year return period). The limitations to modelling are however recognised: the challenges of model validation given the lack of available field data across regional scale models and at open boundaries; assessment and quantification of model uncertainty; model grid size and input data (e.g. bathymetric resolution) limiting the spatial and temporal scales of analysis which can be conducted.

Other tools using flow characterisation data include fully coupled tide to wire models (e.g. Fig. 4) which use CFD models such as Tidal Bladed, a Blade Element Momentum Theory (BEMT) code developed by DNV GL. The model uses input data such as flow speed and direction in the water column, flow shear, turbulence intensity and turbulent length scales to determine the hydrodynamic forces of thrust and torque acting on a TECs blades and rotors. The torque component is subsequently used as input into an electrical generator model which generates electrical power and controls the rotational speed of the rotor which is used as input to the BEMT turbine. The fully-controlled, fully-rated power electronics allow the electrical generator to operate in variable speed and to maximise power capture from the resource by altering the power take off electromechanical torque of the generator. This feedback process depends on the accuracy and availability of measurements such as tidal current speed, mechanical torque and mechanical power.

Validated tide to wire models enable examination of the effect of changing flow conditions on power output, of the effect of extreme metocean conditions and of the effects of fluctuating loads on components within/elements of the rotor and blades during variable speed operation. On the grid side, the effect of grid faults on the operation of the system as well as the quality of exported power to the grid under different realistic scenario can be investigated. These coupled models are in early stages of development see [6], [27].

A further, albeit not mutually exclusive, use of current, wave and turbulent metrics by the tidal industry is to fulfill industrial standards. These standards (outlined in Table III) specify

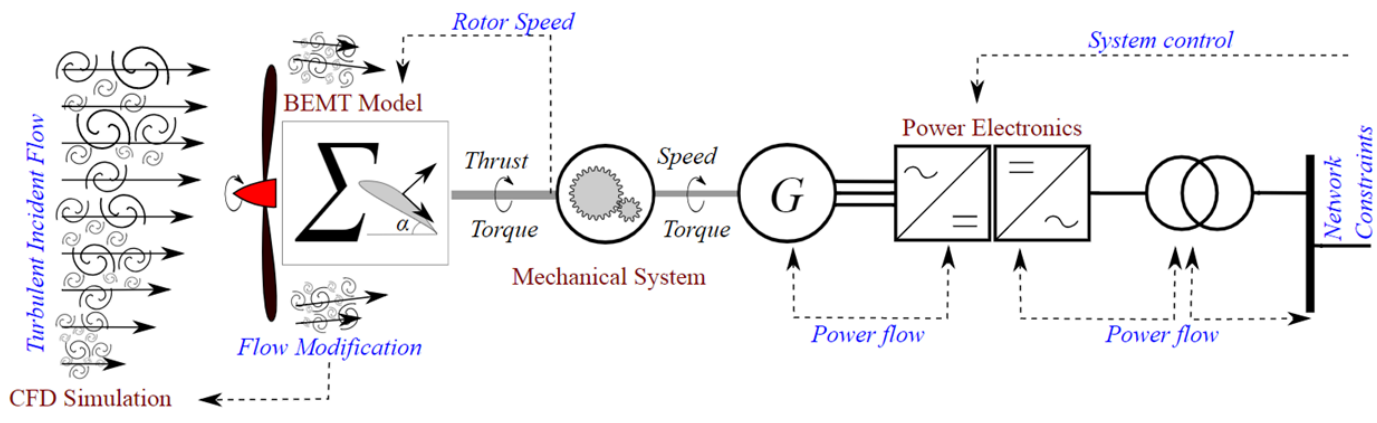

Fig. 4. Tide to wire model: overview schematic (Reproduced with permission from D. Ingram) 
required metrics and provide guidelines for their acquisition and application. The standards seek to ensure consistency in approach across the sector, capturing best practice and enhancing confidence in the emerging industry via verification and certification against the requirements.

\section{INSTRUMENTS USED TO OBTAIN THESE METRICS}

It is inherently challenging to undertake flow characterisation for application to the tidal industry as measurement is required at turbine hub height rather than in close proximity to the sea floor, flows are fast and instruments can invalidate results by disrupting the flow. Further, a compromise must be made between the range of spatial and temporal scales over which measurements would ideally be made and the time, cost and number and type of instruments that must be deployed to achieve this [28].

Significant developments have been achieved in wave, current, and turbulence measurement by the application of acoustic current profilers which measure current using the Doppler shift of backscattered acoustic signals from suspended particulate material moving at the same speed as water particles and whose motion are a proxy for the speed of the local fluid flow. Such instruments are inherently drift free and do not require routine calibration. These instruments sample ranges of the water column remotely without interference in the fluid flow (see Table IV for instruments used by UEdin).

Historically, wave measurements were made using wave rider buoys [29]. In fast flowing tidal sites, their use is limited, being pulled under by the flow although they can provide useful boundary condition inputs into coupled wave/current site models. Where acoustic devices can be used to obtain estimates of wave height and direction, the requirement is removed to deploy multiple sensors to measure waves and currents. As water depths increase, limits are encountered on the frequency, period and height of wave which can be detected via diverging acoustic current profilers, requiring the use of alternative sensors [29].

Acoustic Doppler Velocimeters are a modification of profilers which have been developed to make point measurements of velocity and turbulence in close proximity to boundaries. Up-scaling of this concept to make measurements remote from boundaries is discussed further in Section VI.

Challenges in field deployment and retrieval of acoustic current profilers are exacerbated in tidal stream flow characterisation, for example the levelling of a frame/structure at a tidal site where seabed scouring can result in uneven, rocky surfaces. Similarly, frame retrieval is challenging in high flow, acoustically noisy environments where available time for deployment and retrieval activity is typically limited to short (e.g. 15 to $30 \mathrm{~min}$ ) periods of slack water during neap tides.

As in any acoustic current measurement campaign, but particularly when measuring turbulence for incorporation into TEC design, correction is required for Doppler noise. Doppler noise, the standard error resulting from the estimation of the Doppler shift of finite length acoustic pulses, depends on the sample rate and on bin size (via pulse length) [30]. Without correction for noise, the resultant calculations of turbulence leads to design incorporating unnecessarily conservative safety factors, introducing extra cost into the design, impacting levelised costs of energy [31].

TABLE III

OVERVIEW OF STANDARDS

\begin{tabular}{|c|c|c|}
\hline Standard & Stated purpose & Comment \\
\hline $\begin{array}{l}\text { IEC/TS } 62600-200: 2013 \\
\text { Electricity producing tidal } \\
\text { energy converters-Power perfor- } \\
\text { mance assessment }\end{array}$ & $\begin{array}{l}\text { Systematic methodology for evaluating the } \\
\text { power performance of tidal current energy con- } \\
\text { verters that produce electricity for utility scale } \\
\text { and localised grids }\end{array}$ & $\begin{array}{l}\text { Defines } \\
\text { - TEC rated power } \\
\text { - Rated water velocity } \\
\text { - Power curve production - } \\
\text { - Results reporting }\end{array}$ \\
\hline $\begin{array}{l}\text { IEC/TS } 62600-2: 2016 \\
\text { Marine energy-Wave, tidal and } \\
\text { other water current converters }\end{array}$ & $\begin{array}{l}\text { Provide primary design criteria to ensure engi- } \\
\text { neering integrity throughout the defined design } \\
\text { life of marine energy converters such as wave } \\
\text { and tidal }\end{array}$ & $\begin{array}{l}\text { Site-specific conditions /environmental loads; } \\
\text { Safety factors; } \\
\text { External load cases (extreme, normal); } \\
\text { Failure probability and consequence; } \\
\text { Redundancy }\end{array}$ \\
\hline $\begin{array}{l}\text { IEC/TS } 62600-201: 2015 \\
\text { Marine energy-Wave, tidal and } \\
\text { other water current converters. } \\
\text { Tidal energy resource assess- } \\
\text { ment and characterisation }\end{array}$ & $\begin{array}{l}\text { System for analysing and reporting, through } \\
\text { estimation or direct measurement, the theoret- } \\
\text { ical tidal current energy resource in oceanic } \\
\text { area...that may be suitable for the installation } \\
\text { of arrays of TECs }\end{array}$ & $\begin{array}{l}\text { Staged approach to calculation of resource as- } \\
\text { sessment with increasing level of detail from } \\
\text { feasibility stage to design layout. } \\
\text { Outlines data collection for calibration and val- } \\
\text { idation of hydrodynamic models. }\end{array}$ \\
\hline $\begin{array}{l}\text { DNVGL-ST-0164 } \\
\text { Tidal turbines }\end{array}$ & $\begin{array}{l}\text { Principles, technical requirements and guidance } \\
\text { for design, construction and in-service inspec- } \\
\text { tion of tidal turbines. }\end{array}$ & $\begin{array}{l}\text { Requirements for site characterisation; } \\
\text { Limit state approach to design; } \\
\text { Addresses design loads and associated return } \\
\text { periods (e.g. } 1 \text { and } 50 \text { year); } \\
\text { Load effects and load combination analysis }\end{array}$ \\
\hline $\begin{array}{l}\text { DNVGL-RP-C205 } \\
\text { Environmental conditions and } \\
\text { environmental loads }\end{array}$ & $\begin{array}{l}\text { Guidance for modelling, analysis and prediction } \\
\text { of environmental conditions as well guidance } \\
\text { for calculating environmental loads acting on } \\
\text { structures }\end{array}$ & $\begin{array}{l}\text { Specific to wind, wave, current loading on a } \\
\text { range of structures. } \\
\text { Outlines metrics, their statistical derivation and } \\
\text { the methodology for load calculation on e.g. } \\
\text { slender members and large volume structures }\end{array}$ \\
\hline
\end{tabular}


TABLE IV

Example Acoustic CurRent Profilers Deployed in Flow Characterisation

\begin{tabular}{|c|c|c|c|c|c|c|c|}
\hline & & $\begin{array}{l}\text { Beam } \\
\text { configuration }\end{array}$ & $\begin{array}{l}\text { Range from } \\
\text { sensor (m) }\end{array}$ & $\begin{array}{l}\text { Maximum } \\
\text { sample } \\
\text { frequency } \\
(\mathrm{Hz})\end{array}$ & $\begin{array}{l}\text { Pulse } \\
\text { frequency } \\
\text { (MHz) }\end{array}$ & $\begin{array}{l}\text { No. } \\
\text { operating } \\
\text { beams }\end{array}$ & $\begin{array}{l}\text { Minimum bin } \\
\text { length }\end{array}$ \\
\hline D-ADP & Nortek AWAC & Divergent & 35 & 1 & 1 & $3-5$ & $1.0 \mathrm{~m}$ \\
\hline D-ADP & RDI ADCP & Divergent & 50 & 2 & 0.6 & 4 & $0.5 \mathrm{~m}$ \\
\hline D-ADP & Nortek ADCP & Divergent & 60 & 8 & 0.5 & 5 & $0.5 \mathrm{~m}$ \\
\hline SB-ADP & Nortek ADCP & Single & 20 & 4 & 1 & 1 & $0.4 \mathrm{~m}$ \\
\hline $\mathrm{ADV}^{*}$ & Nortek ADV & Convergent & 0.15 & 64 & $0.1-0.25$ & 3 & $5 \mathrm{~mm}$ \\
\hline C-ADP & Nortek ADCP & Convergent & 4 & 4 & 1 & 4 & $0.4 \mathrm{~m}$ \\
\hline
\end{tabular}

*point measurement

D-ADP Divergent Acoustic Doppler Profiler; ADV Acoustic Doppler Velocimeter; SB-ADP Single Beam ADP; C-ADP Converging ADP

\section{INDUSTRY-ACADEMIC PROJECTS}

A range of significant industry/academic projects have been funded by pan-European and national entities to facilitate and accelerate the exploitation of marine renewable energy (MRE) which includes tidal energy. This includes projects such as Equimar (2008-2011) developing protocols to standardise assessment of different MRE technologies; SI Ocean (20122014) identifying gaps and barriers/opportunities to adoption of MRE; DTOcean (2013-2016) and DTOcean plus (20182020) developing design tools to support option selection, development and deployment in the MRE sector.

To further understand the flow environment in which TECs operate and derive industrially relevant metrics, a range of European and UK projects have, or are, being run with a variety of certification bodies, academic and industrial partners (Table V). From these projects, a number of lessons can be drawn that are being incorporated into subsequent TEC/flow characteriation projects and which also have wider applicability. These include:

- Scheduling: When a flow characterisation campaign is associated with an industrial partner operating a TEC, the measurement campaign timeline and intervention opportunities are driven by TEC installation and maintenance plans. This interaction influences the time available to develop instrument packages and affects when the instruments can be accessed in addition to weather and tidal constraints to access. This occurred on ReDAPT (Table V) which involved the deployment of a range of acoustic current profilers over 36 months on and around the Alstom DEEPGen IV TEC and RealTide (Table V) which involves the deployment of a range of acoustic current profilers on and around the Sabella TEC.

- Communication: Close co-operation with the operator of the device is paramount to the success of the measurement campaign. Potential seabed instrument locations may be rendered unusable by vessel mooring positions or cable laying routes, constraints which should be understood early in the campaign's planning phase. To mount instruments on the TEC, upfront agreement is required on location, particularly where additional complexity is introduced with, for example, instruments mounted on a rotating hub (see Section VI). Any penetrations required to mount instruments should be incorporated into TEC structural design and any material incompatibilities identified and designed out or mitigated. To understand the measurements being made by the instruments, the instrument operator needs information about the TEC, such as the operational status of the turbine, the rotational direction of the blade, the yaw of the turbine (if applicable), power generation and blade loading. To protect their company and assets in an emerging yet competitive industry, TEC developers can be particularly sensitive about data and information confidentiality. Confidentiality agreements are required to clearly establish any limitations on the use and the dissemmination of data obtained.

- Reference datum: In order to ensure data acquired from instrumentation can be utilised to draw conclusions between instruments and across measurement campaigns, a number of datum must be established:

A period of stationarity must be determined, over which there is a stable mean and variation. For wave characterisation, periods of 3 hours are typically used, over which a constant significant wave height and spectral peak period are assumed [17]. For turbulence calculations from field data, periods of pseudo-stationarity of 5 or $10 \mathrm{~min}$ have been used, over which mean velocity and its variation (i.e. turbulence) are assumed constant [36].

The hub height of the turbine may typically be used as the reference $(z)$ location within the water column, although alternative reference locations may exist, e.g. the swept area of the turbine blade or the mean water level. The reference velocity will be measured from a specific $x, y$ location by a particular instrument.

The measurement scale can range from localised measurement at hub height, to the swept area of the rotor, to the validation of hydrodynamic models which typically have areas of higher resolution around the areas of interest e.g. TEC location. The target scale must be agreed at the outset of the measurement campaign design given the objective of the campaign. 
TABLE V

Selected Industrial Academic Partnerships Furthering Flow Characteriation for the Tidal Sector

\begin{tabular}{|c|c|c|}
\hline $\begin{array}{l}\text { Project (abbreviation) } \\
\text { Funder, duration, value (US \$ million), partners }\end{array}$ & Key objectives & $\begin{array}{l}\text { Key flow characterisation outputs } \\
\text { (anticipated) }\end{array}$ \\
\hline $\begin{array}{l}\text { Reliable Data Acquisition Platform for Tidal (ReDAPT) } \\
\text { project [4] } \\
\text { ETI, UK; } 2010 \text { to 2015; } \$ 16.2 \mathrm{~m} \\
\text { Alstom; E.ON; EDF; DNV GL; Plymouth Marine Laboratory; } \\
\text { European Marine Energy Centre (EMEC); University of } \\
\text { Edinburgh (UEdin) }\end{array}$ & $\begin{array}{l}\text { Design, installation, operation of a } 1 \mathrm{MW} \\
\text { horizontal axis turbine, Orkney } \\
\text { Multi year field measurement campaign for } \\
\text { tidal energy resource characterisation }\end{array}$ & $\begin{array}{l}\text { Calibration \& validation data for BEMT } \\
\text { Tidal Bladed model tool [32] } \\
\text { Site-wide hydrodynamic model (MIKE 3) } \\
\text { Long term, multi instrument dataset with } \\
\text { application to model validation } \\
\text { Effect of wave climate on turbulence } \\
\text { characteristics [33] }\end{array}$ \\
\hline $\begin{array}{l}\text { Advanced monitoring, simulation and control of tidal } \\
\text { devices in unsteady, highly turbulent realistic tidal } \\
\text { environments (RealTide) [6] } \\
\text { H2020, EU; } 2018 \text { to 2020; } \$ 5.7 \mathrm{~m} \\
\text { Sabella; Bureau Veritas; Institut Francais de Recerche } \\
\text { pour l'Exploitation de la MER (IFREMER); 1-Tech; Ingeteam } \\
\text { Power Technology S.A.; EnerOcean S.L.; UEdin }\end{array}$ & $\begin{array}{l}\text { Combine flow measurement, condition } \\
\text { monitoring and turbine components with } \\
\text { tide-to-wire modelling to design reliable } \\
\text { power take off and control systems deliv- } \\
\text { ering grid compliant energy }\end{array}$ & $\begin{array}{l}\text { Detailed tide to wire simulator incorporat- } \\
\text { ing environmental and machine models } \\
\text { Site flow characterisation with and without } \\
\text { waves } \\
\text { Validated hydrodynamic model to comple- } \\
\text { ment and extrapolate field data }\end{array}$ \\
\hline $\begin{array}{l}\text { Resource Characterisation to Reduce the Cost } \\
\text { of Energy through Coordinated Data } \\
\text { (RESOURCECODE) [34] } \\
\text { Oceaneranet EU; } 2019 \text { to 2021; } \$ 2.3 \mathrm{~m} \\
\text { EMEC; IFREMER; University College Dublin; Ecoles } \\
\text { Centrale Nantes; UEdin; Innosea; OceanData Lab; SmartBay } \\
\text { Ireland }\end{array}$ & $\begin{array}{l}\text { Creation of marine data toolbox to } \\
\text { facilitate decision making. } \\
\text { Open data platform } \\
\text { Cross validation of models }\end{array}$ & $\begin{array}{l}\text { Accessible metocean data } \\
\text { Tools to utilise metocean data in design } \\
\text { Validated high resolution hydrodynamic } \\
\text { model of French, Irish and UK waters }\end{array}$ \\
\hline $\begin{array}{l}\text { Enabling Future Arrays in Tidal (ENFAIT) project [35] } \\
\text { EC H2020, EU; } 2017 \text { to 2022; } \$ 23 \mathrm{~m} \\
\text { Nova Innovation Ltd; Offshore Renewable Energy Catapult; } \\
\text { ELSA; SKF; Mojo Maritime Ltd; UEdin; Wood Group; RSK } \\
\text { Environment; HMK Technical Services Ltd }\end{array}$ & $\begin{array}{l}\text { Develop, operate, decommission 6-turbine, } \\
\text { grid connected array over } 5 \text { years to prove } \\
\text { cost-competitiveness of tidal energy }\end{array}$ & $\begin{array}{l}\text { Array model validation } \\
\text { In-situ measurement and characterisation } \\
\text { of tidal array wake interactions }\end{array}$ \\
\hline
\end{tabular}

A common time stamp is required between the TEC, its ancilliary equipment and the instruments. Any drift in time stamping over the duration of the measurement campaign must be understood in order to be addressed in the post processing of data.

- Instrument controller: If a TEC's power and communications systems are used by the measurement campaign, there are multiple interfaces with the operators systems to understand, manage and test. Such interfacing may also generate the requirement for external enclosures housing additional instrument control, fusing and remote diagnostic equipment. The ability to receive real time data from instruments and remotely change their settings, despite the additional complexity associated with TEC interfacing, represents significant benefits over standalone deployments of acoustic current profilers where no information can be recovered from the system until retrieval days to weeks after deployment.
- Heterogeneity of location: the spatial and temporal heterogeneity at tidal stream sites must inform the design and duration of measurement campaigns and subsequent use of the data. The site topography can e.g. constrain local flow and lead to the shedding of eddy structures, affecting current velocity. This heterogeneity can be seen in the ReDAPT project data, where two D-ADPs were deployed approximately $80 \mathrm{~m}$ apart at points $6 \mathrm{a}$ and $6 \mathrm{~b}$ (Fig. 5a), for 85 and 71 days respectively from 17/09/2014. The depth profile of streamwise velocity is shown for the ebb tide at both D-ADP locations with the data being plotted against reference velocity bins from $0.6 \mathrm{~m} / \mathrm{s}$ to $3.8 \mathrm{~m} / \mathrm{s}$ using bin widths of $0.4 \mathrm{~m} / \mathrm{s}$ (Fig. $5 \mathrm{~b}$ ). The flow profiles measured by sensor $6 \mathrm{~b}$ (circles) resemble those characterised by the power law [14]. A distortion of this profile occurs at $6 \mathrm{~b}$, visible in the upper half of the water column. This distortion is present only on the ebb tide [36] and may be due to the influence of a nearby headland. 


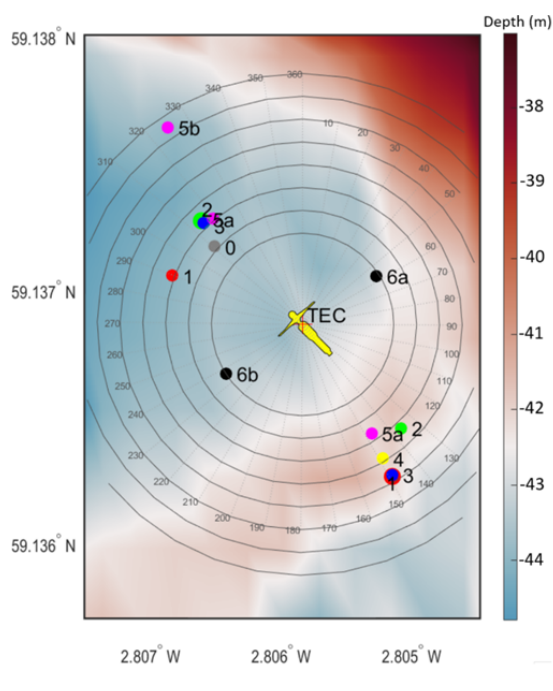

(a)

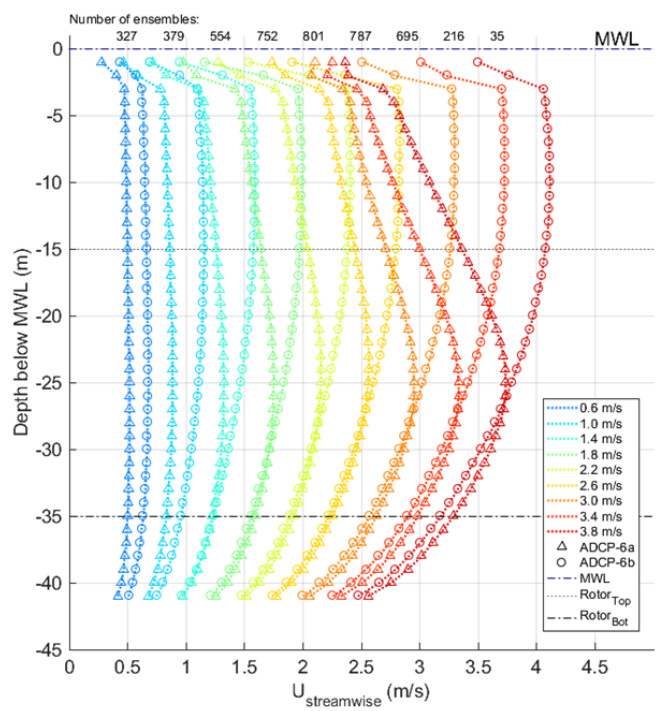

(b)

Fig. 5. Vertical variation in current velocity at ReDAPT locations $6 \mathrm{a} \& 6 \mathrm{~b}, 80 \mathrm{~m}$ apart a) Locations of D-ADP [36] b) Streamwise velocity depth profiles

- Distortion of compass readings: guidance such as the IEC standard [10] provides recommendations for mitigation of compass distortion e.g. use of non-ferrous frames and associated components and compass calibration occurring in the deployment frame away from any sources of magnetism. Where in-situ calibration or re-calibration is not achievable, alternative methods of instrument alignment can be used, e.g., via ROVs as performed in ReDAPT.

Data management and quality control (QC) /assurance (QA) is key to ensuring the validity of the data captured by instruments and subsequent data dissemination and utilisation. Briefly considered here, this complex subject is covered in detail in manuals such as [37]:

- Quality assurance (hardware checks): QA includes the checking of hardware, for example ensuring that instruments are checked and calibrated pre-deployment, that corrosion and bio-fouling are mitigated and that timely maintenance is conducted.

- Quality control (data checks): QC processes check both data integrity i.e. that the expected volume of data has arrived in the expected format, and also the validity of the data. Data validity checks involve the identification and management of unrepresentative or anomalous data. This requires the selection of QC parameters associated with e.g. sensor health, signal quality, current velocity and the overall profile. When these checks are applied to the data, flags are inserted based on defined thresholds, providing subsequent users with an indication of data quality. Given the quantity of data generated in a multiinstrument campaign over a period of weeks to months, automation of QC processes should be targeted.

- Data storage: Data which has been quality controlled must be held securely while being accessible and searchable to the target audience. This typically involves the use of a relational database. Geo-referencing of the data facilitates its integration with other geospatial measurements and geographical information system (GIS) querying/presentation. Metadata (information about the data, its acquisition and processing) is recorded and stored in line with relevant standards such as the Marine Environmental Data and Information Network ISO19139 discovery metadata profile

- Uncertainties: Uncertainties should be identified and quantified both for models e.g. amount of energy lost by seabed friction and instruments e.g. ADCP error velocity increasing with distance from the instrument. Albeit it is recognised [11] that there is a paucity of field and model data to obtain statistical significance.

- Clustering: Unlike data collected in the lab, field data obtained over a period of time under a variety of conditions requires filtering and clustering to statistically characterise the tidal energy site. Clustering occurs on a variety of parameters: those associated with instruments e.g. configuration, availability, location, orientation; those associated with the project e.g. turbine installed, turbine operational; those associated with flow characteristics e.g. maximum wave height, wave period. During the data acquisition campaign, there may be periods of time of instrument non-availability. It was found, for example, on ReDAPT that despite data being collected over a period of 3 years, once data is filtered for particular set of conditions e.g. no waves, ebb tide, turbine operational and current speed between cut in and cut out speed, only a limited number of samples remain. This re-inforces the need for a calibrated, validated, coupled wave-tidal hydrodynamic model which generates data to complement direct measurements [14]. 


\section{Advanced Sensor Configuration}

From Section V, flow characterisation research challenges in relation to TEC mounted/associated instruments are highlighted as: a) measuring turbulence at TEC relevant locations b) mounting instruments at TEC-relevant locations c) mitigating accelerated failure. Fig. 6 illustrates this via an idealised configuration of TEC mounted/associated instruments but doesn't address the differences in measurement locations required by different TEC concepts (e.g. fixed/floating, Table I) which would inform measurement campaign specification.

Measuring turbulence at TEC relevant locations: Initial development of a convergent beam ADP has been presented in [38] and [39] with this work aiming to overcome the limitations of acoustic current profilers in quantifying turbulence, including the assumption of flow homogeneity between DADP beams. While valid for larger eddies, coherent turbulent structures smaller than beam separation cannot be resolved, an inaccuracy which increases away from the instrument due to beam divergence. Further, the full Reynolds stress tensor cannot be resolved with a single four or five beam instrument (Table II). In currently available convergent instruments (ADV), the proximity of the sample volume to the instrument means it cannot readily be used to profile turbulence in the water column. The C-ADP instrument uses convergent beams to achieve high resolution, three-dimensional measurements of mean and turbulent flow, thereby obtaining higher resolution information on the spatial coherence of velocity fields. Initial verification of concept as part of the ReDAPT deployment [38] demonstrated close agreement in the velocity measurements made by the C-ADP and an D-ADP, as well as comparable vertical velocity measurement between the C-ADP and a single beam ADP. Instrument development and testing continues, including focal point scanning.

Mounting instruments at TEC relevant locations: Mounting standard acoustic current profilers at hub height involves instrument integration with the TEC to obtain measurement of flow velocity and turbulence with lower uncertainty and direct measurement of inflow/wake lengthscales. Such integration on a rotating hub can involve the use of a bespoke slip ring although the introduction of additional complexity and potential failure modes may not be acceptable to a TEC developer, necessitating novel power and communication solutions. Other potential solutions include the compliant mooring of instruments tethered at the relevant depth in the water column with correction for platform motion [28] [40].

Mitigating accelerated failures During the ReDAPT project, multiple wet-mateable connector failures shortened the duration of the measurement campaign. Potential failure causes include the highly oxygenated environment accelerating failure and pressure oscillations in rubber casing due to tidal and wave cycles. While minimising the cost of solutions, greater resilience is required along with remote diagnostics. Instruments and their ancilliaries should be included in system-wide inspection and maintenance procedures, addressing e.g.biofouling removal.

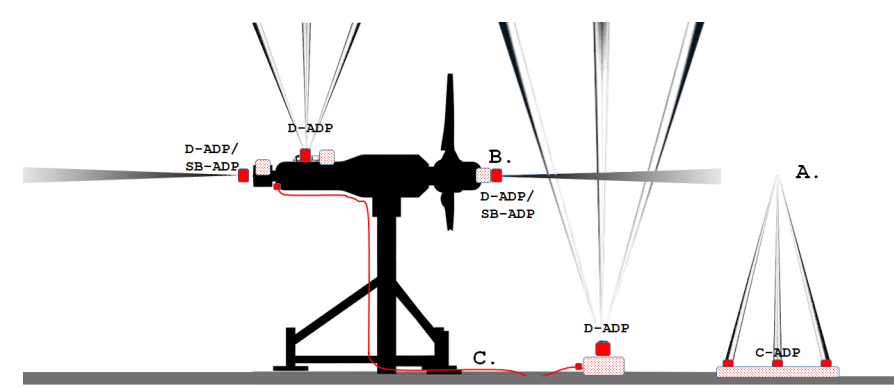

Fig. 6. Multi-instrument deployment around fixed bottom TEC illustrating research challenges A. Measurement at TEC relevant location B. Mounting instruments at TEC relevant location C. Mitigating accelerated failures

\section{CONCLUSION}

This paper has given examples of the types of tidal stream devices currently in operation and outlined the application of current, wave and turbulence metrics in use by the tidal industry. It has reviewed the instruments deployed to capture these current, wave and turbulence metrics and their use in a number of projects. Gaps identified have led to the ongoing development of advanced sensor configuration seeking to advance measurement of turbulence with direct application to the design and development of TECs and their array configuration. Field measurement data is key to the validation of models which are used to understand and predict a site's hydrodynamics and the resultant loading on TECs. Model validation, coupled with uncertainty assessment throughout the chain of data acquisition, data processing and data utilisation generates confidence in design tools. As the tidal stream industry continues to develop, and an increasing number and size of tidal arrays are deployed, engineering tools supported by field-validated models are key to ensuring the industry reliably produces power which is competitive with other forms of energy, notably wind.

\section{ACKNOWLEDGMENT}

The Energy Technology Institute and RCUK Energy programme funded this work as part of the IDCORE programme (EP/J500847/1). This work is also funded under the European Commission's Horizon 2020 programme via the RealTide project (Grant Agreement no. 727689).

\section{REFERENCES}

[1] OEF, "OCEAN ENERGY STRATEGIC ROADMAP BUILDING OCEAN ENERGY FOR EUROPE,” Tech. Rep., 2016.

[2] I. A. Milne, A. H. Day, R. N. Sharma, and R. G. Flay, "The characterisation of the hydrodynamic loads on tidal turbines due to turbulence," Renewable and Sustainable Energy Reviews, vol. 56, pp. 851-864, 2016.

[3] L. Myers and A. Bahaj, "An experimental investigation simulating flow effects in first generation marine current energy converter arrays," Renewable Energy, vol. 37, no. 1, pp. 28-36, 12012.

[4] "ReDAPT." [Online]. Available: https://www.eti.co.uk/programmes/ marine/redapt

[5] "FloWTurb." [Online]. Available: https://gow.epsrc.ukri.org/ NGBOViewGrant.aspx?GrantRef=EP/N021487/1

[6] "RealTide." [Online]. Available: https://www.realtide.eu/home 
[7] S. Draycott, B. Sellar, T. Davey, D. Noble, V. Venugopal, and D. Ingram, "Capture and simulation of the ocean environment for offshore renewable energy," Renewable and Sustainable Energy Reviews, vol. 104, pp. 15-29, 42019.

[8] S. J. Couch and I. Bryden, "Tidal current energy extraction: Hydrodynamic resource characteristics," Proceedings of the Institution of Mechanical Engineers, Part M: Journal of Engineering for the Maritime Environment, vol. 220, no. 4, pp. 185-194, 122006.

[9] A. Uihlein and D. Magagna, "Wave and tidal current energy - A review of the current state of research beyond technology," Renewable and Sustainable Energy Reviews, vol. 58, pp. 1070-1081, 2016.

[10] IEC, IEC TS 62600-200 Marine energy - Wave, tidal and other water current converters - Part 200: Electricity producing wave energy converters - Power performance assessment, 2012.

[11] _ IEC TS 62600-201 : Marine energy Wave, tidal and other water current converters energy converters Tidal energy resource assessment and characterization, 2015.

[12] DNV-GL, "DNVGL-ST-0.164: Tidal turbines," Tech. Rep. October, 2015. [Online]. Available: http://www.dnvgl.com

[13] IEC, IEC TS 62600-2 : 2016 Marine energy Wave, tidal and other water current converters. Part 2: Design requirements for marine energy systems, 2015.

[14] M. Lewis, S. Neill, P. Robins, M. Hashemi, and S. Ward, "Characteristics of the velocity profile at tidal-stream energy sites," Renewable Energy, vol. 114, pp. 258-272, 122017.

[15] M. Guerra and J. Thomson, "Turbulence measurements from five-beam acoustic doppler current profilers," Journal of Atmospheric and Oceanic Technology, vol. 34, no. 6, pp. 1267-1284, 62017.

[16] S. B. Pope, Turbulent Flows. Cambridge: Cambridge University Press, 2000.

[17] S. R. Massel, Ocean Surface Waves: Their Physics and Prediction. World Scientific, 2 1996, vol. 11.

[18] Polagye B, B. V. Cleve, K. Kirkendall, and K. Copping, "Environmental effects of tidal energy development In: Proceedings of a scientific workshop. Seattle: NOAA;”, Tech. Rep., 2011.

[19] Z. Yang and A. Copping, Marine renewable energy: Resource characterization and physical effects, 2017.

[20] C. Frost, I. Benson, P. Jeffcoate, B. Elsäßer, and T. Whittaker, "The Effect of Control Strategy on Tidal Stream Turbine Performance in Laboratory and Field Experiments," Energies, vol. 11, no. 6, p. 1533, 6 2018.

[21] S. Draycott, G. Payne, J. Steynor, A. Nambiar, B. Sellar, and V. Venugopal, "An experimental investigation into non-linear wave loading on horizontal axis tidal turbines," Journal of Fluids and Structures, vol. 84, pp. 199-217, 12019

[22] P. Mycek, B. Gaurier, G. Germain, G. Pinon, and E. Rivoalen, "Experimental study of the turbulence intensity effects on marine current turbines behaviour. Part II: Two interacting turbines," Renewable Energy, vol. 68 , pp. 876-892, 82014

[23] S. Tatum, C. Frost, M. Allmark, D. ODoherty, A. Mason-Jones, P. Prickett, R. Grosvenor, C. Byrne, and T. ODoherty, "Wavecurrent interaction effects on tidal stream turbine performance and loading characteristics," International Journal of Marine Energy, vol. 14, pp. 161-179, 62016.
[24] M. Lewis, S. Neill, M. Hashemi, and M. Reza, "Realistic wave conditions and their influence on quantifying the tidal stream energy resource," Applied Energy, vol. 136, pp. 495-508, 122014.

[25] P. Galloway, L. Myers, and A. Bahaj, "Studies of a scale tidal turbine in close proximity to waves," in Third International Conference and Exhibition on Ocean Energy, Spain., 2010, p. 6 pp.

[26] E. E. Lust, L. Luznik, K. A. Flack, J. M. Walker, and M. C. Van Benthem, "The influence of surface gravity waves on marine current turbine performance," International Journal of Marine Energy, vol. 3-4, pp. 27 40, 122013.

[27] "SupergenMarine." [Online]. Available: www.supergen-marine.org.uk

[28] S. Harding, L. Kilcher, J. Thomson, S. Harding, L. Kilcher, and J. Thomson, "Turbulence Measurements from Compliant Moorings. Part I: Motion Characterization," Journal of Atmospheric and Oceanic Technology, vol. 34, no. 6, pp. 1235-1247, 62017.

[29] P. Kasinatha Pandian, O. Emmanuel, J. P. Ruscoe, J. C. Side, R. E. Harris, S. A. Kerr, and C. R. Bullen, "An overview of recent technologies on wave and current measurement in coastal and marine applications," Journal of Oceanography and Marine Science, vol. 1, no. 1, pp. 1-10, 2010.

[30] J. Thomson, B. Polagye, V. Durgesh, and M. C. Richmond, "Measurements of turbulence at two tidal energy sites in puget sound, WA," IEEE Journal of Oceanic Engineering, vol. 37, no. 3, pp. 363-374, 2012.

[31] J.-B. Richard, J. Thomson, B. Polagye, and J. Bard, "Method for identification of Doppler noise levels in turbulent flow measurements dedicated to tidal energy," International Journal of Marine Energy, vol. 3-4, pp. 52-64, 122013

[32] S. G. Parkinson and W. J. Collier, "Model validation of hydrodynamic loads and performance of a full-scale tidal turbine using Tidal Bladed," International Journal of Marine Energy, vol. 16, pp. 279-297, 122016.

[33] B. G. Sellar, D. R. Sutherland, D. M. Ingram, and V. Venugopal, "Measuring waves and currents at the European marine energy centre tidal energy test site," in OCEANS 2017 - Aberdeen. IEEE, 62017, pp. 1-7.

[34] "Scottish led European project announces funding." [Online]. Available: https://www.scottish-enterprise-mediacentre.com/news/

[35] "ENFAIT." [Online]. Available: https://www.enfait.eu/the-project/

[36] B. Sellar, G. Wakelam, D. Sutherland, D. Ingram, and V. Venugopal, "Characterisation of Tidal Flows at the European Marine Energy Centre in the Absence of Ocean Waves," Energies, vol. 11, no. 1, p. 176, 1 2018.

[37] Integrated Ocean Observing System, "Manual for Real-Time Quality Control of In-Situ Current Observations," Tech. Rep., 2015. [Online]. Available: http://www.ioos.noaa.gov/qartod/welcome.html

[38] B. Sellar, S. Harding, and M. Richmond, "High-resolution velocimetry in energetic tidal currents using a convergent-beam acoustic Doppler profiler," Measurement Science and Technology, vol. 26, no. 8, p. 085801,82015

[39] A. E. Hay, L. Zedel, S. Nylund, R. Craig, and J. Culina, "The Vectron," 2015 IEEE/OES 11th Current, Waves and Turbulence Measurement, CWTM 2015, no. $10 \mathrm{~m}, 2015$.

[40] L. F. Kilcher, J. Thomson, S. Harding, and S. Nylund, "Turbulence Measurements from Compliant Moorings. Part II: Motion Correction," Journal of Atmospheric and Oceanic Technology, vol. 34, no. 6, pp. 1249-1266, 62017. 